Dermatology 2011;223:311-315

DOI: $\underline{10.1159 / 000334805}$

\section{Eosinophilia during Psoriasis Treatment with TNF Antagonists}

\author{
Bartosz Malisiewicz a , Carla Murer a , Jana Pachlopnik Schmid ${ }^{\mathrm{b}}$, \\ Lars E. French ${ }^{\text {a }}$, Peter Schmid-Grendelmeier ${ }^{\text {a }}$, \\ Alexander A. Navarini ${ }^{\text {a }}$ \\ ${ }^{a}$ Department of Dermatology and Allergology, University

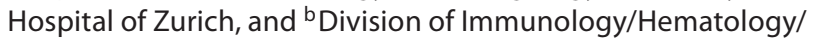 \\ BMT, University Children's Hospital Zurich, Zurich, Switzerland
}

\section{Key Words}

Psoriasis vulgaris - Eosinophilia - Tumour necrosis factor $\alpha$. Adalimumab $\cdot$ Etanercept

\section{Introduction}

Psoriasis is dependent on Th1- and Th17-polarized CD4 T cells that produce pro-inflammatory cytokines (such as TNF- $\alpha$ ) and thus prompt the development of acanthosis and papillomatosis [1]. Blocking TNF- $\alpha$ greatly improves clinical outcomes $[2,3]$ and results in fewer (and generally milder) side effects than observed for older drugs (e.g. cyclosporin A or methotrexate). Common side effects are temporary headaches, nasopharyngitis, upper respiratory tract infections, injection site reactions, eczema and (more rarely) vasculitis [4]. Here, we report on 3 patients with psoriasis (variously with and without joint involvement) who developed isolated eosinophilia during TNF blockade.

\section{Patient 1}

A 46-year-old Caucasian male with a 30-year history of severe psoriasis and psoriatic arthritis was treated with a combination of adalimumab, anthralin and topical steroids. Prior to treatment, slight eosinophilia had been noted $(730 / \mu$ l of blood, relative to an upper normal limit of $700 / \mu \mathrm{l})$. The serum tryptase level was normal $(<11.7 \mathrm{U} / \mathrm{l})$. The patient had a history of seasonal allergic rhinitis but no other signs of atopy. Total IgE was $<100 \mathrm{kU} / \mathrm{l}$. Prior to initiation of adalimumab treatment, the patient had a Psoriasis Area and Severity Index (PASI) score of 11.3, which fell to 0.1 after 4.5 months of treatment. After 3.25 months of therapy, he developed eosinophilia $(1,550 / \mu \mathrm{l}$; fig. 1a). Eosinophilic cationic protein (ECP) was also elevated $(38.20 \mu \mathrm{g} / \mathrm{l}$; normal range $1.8-13.3 \mu \mathrm{g} / \mathrm{l})$. A parasite screen was negative, and total IgE levels remained normal. No signs of a haematological disorder were found. The patient also reported transient urticarial skin changes that developed after the onset of adalimumab treatment but had resolved before clinical examination. After discontinuation of adalimu- mab, ECP levels and eosinophil counts fell to normal values within 5 months. However, the PASI increased to 10.1. Etanercept was introduced, and the eosinophil count was still in the normal range 3 months later.

\section{Patient 2}

A 55-year-old Caucasian female with a 13-year history of plaque-type psoriasis and psoriatic arthritis had failed to show satisfactory results after receiving anthralin, topical steroids, calcineurin inhibitors, narrow-band UVB and psoralen + UVA. Combination treatment with adalimumab, anthralin and topical steroids was initiated. The complete blood count was normal. Over the next 11 months, the PASI fell from 7.7 to 0 . After 8.5 months of therapy, she developed eosinophilia $(1,250 / \mu \mathrm{l}$, peaking at $1,480 / \mu$ l; fig. 1b). After 3.5 months, ECP was elevated $(149 \mu \mathrm{g} / \mathrm{l})$. A parasite screen of a faecal specimen revealed asymptomatic colonization with the facultative pathogen Dientamoeba fragilis, which we decided not to treat [5]. The total blood IgE level was not elevated, and tryptase was slightly elevated (14.7 $\mathrm{U} / \mathrm{l}$ ). The haematological profile was normal. After a switch from adalimumab to methotrexate, the eosinophilia resolved within 10 days.

\section{Patient 3}

A 24-year-old Caucasian male had been consulting us for phototherapy- and isotretinoin-resistant plaque psoriasis without joint involvement for 11 years. He had an atopic disposition and a history of resolved hepatitis C. With $2 \times 25 \mathrm{mg}$ etanercept per week, the PASI fell from 15.1 to 1.9 within a year. During the first course of treatment, above-normal eosinophil counts $>700 / \mu \mathrm{l}$ alternated with normal values (fig. 1c). At a value of $830 / \mu l$, treatment was temporarily withdrawn, and the eosinophil count normalized. When etanercept was re-introduced, low-level eosinophilia recurred $(740 / \mu \mathrm{l})$. During subsequent treatment with adalimumab, however, the eosinophil count rose up to $1,270 / \mu l$ and then spontaneously resolved to values at the upper limit of the normal range $(690 / \mu l)$. No clinical findings were associated with these fluctuations of eosinophil counts other than the temporal association with the TNF- $\alpha$ antagonists. A parasite screen was normal. Total IgE levels were elevated $(360 \mathrm{kU} / \mathrm{l})$, as was ECP. The SX1 inhalant allergen screen was positive. Serum tryptase was not elevated. The haematological profile was normal. An overview of the clinical data of all 3 patients is shown in table 1. Eosinophils were significantly increased during treatment with adalimumab compared to treatment with etanercept or no biological agent (fig. 1d).

\section{Discussion}

The introduction of biologicals has improved treatment efficacy in several chronic inflammatory disorders. Early identifica-

\section{KARGER}

(c) 2012 S. Karger AG, Basel

Fax +41613061234 E-Mail karger@karger.ch www.karger.com 

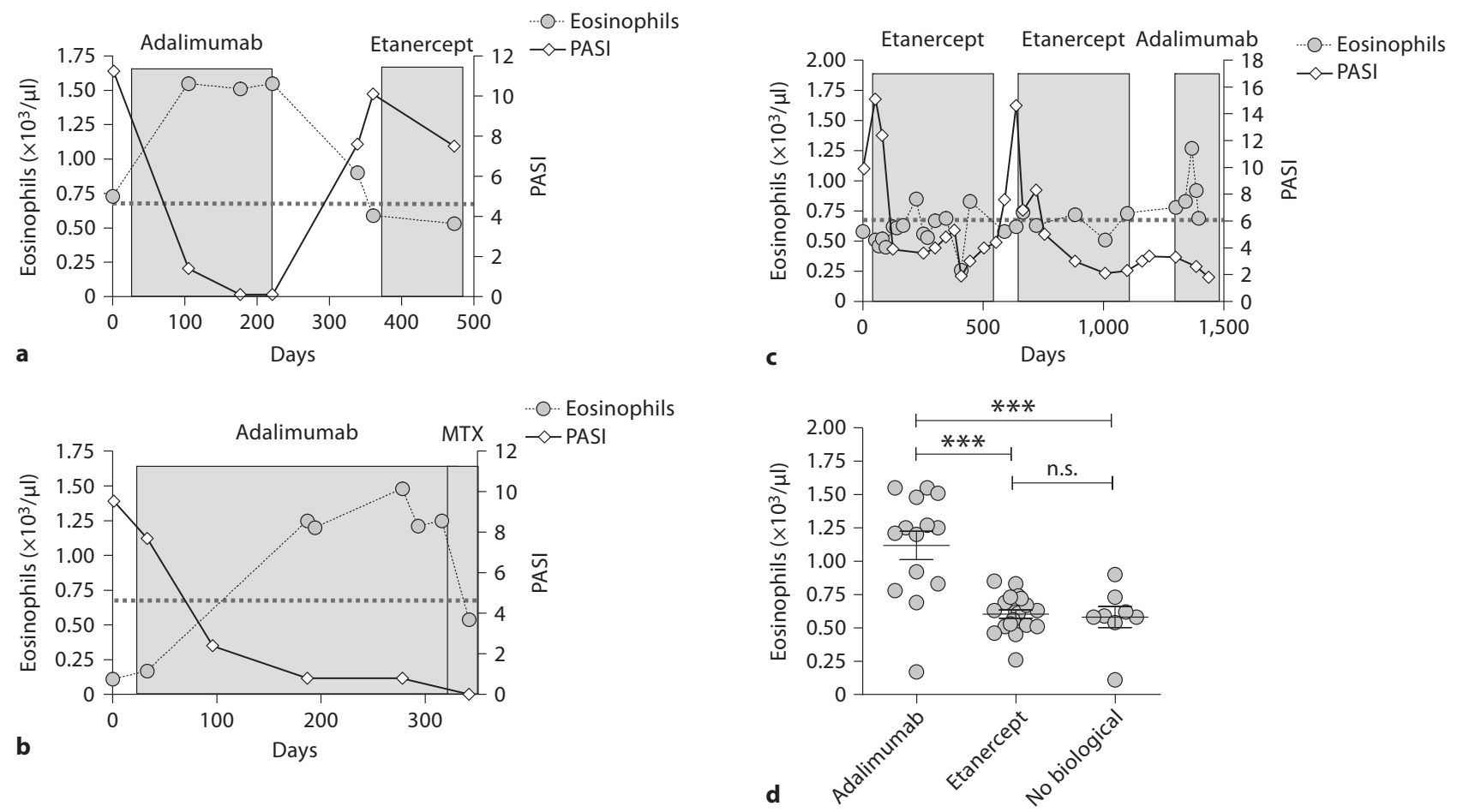

Fig. 1. a-c Changes in eosinophil count and PASI values over time, for patients 1, 2 and 3, respectively. Grey boxes indicate the periods of treatment with biologicals or methotrexate (MTX). The dashed line shows the cutoff value of the eosinophilia $(700 / \mu \mathrm{l})$. d Scatter plot of eosinophil numbers measured during adalimumab versus etanercept treatment versus no treatment. ${ }^{* *} \mathrm{p}<0.001$; n.s. $=$ non-significant.

tion and reporting of potential drug-related side effects is an important task for clinicians. However, deviations from normal laboratory values must be interpreted in a clinical context, and not all changes are necessarily of clinical relevance. Here, we report 3 cases of eosinophilia that were temporally associated with the administration of TNF antagonists. In 1 of 3 patients, eosinophilia resolved spontaneously during adalimumab treatment. Two patients developed de novo eosinophilia, and 1 patient's preexisting eosinophilia worsened. Some cases of eosinophilic pathology associated with TNF- $\alpha$ inhibitors have been observed before. Some cases of eosinophilic pathology associated with TNF- $\alpha$ inhibitors have been observed before. Etanercept-induced eosinophilic, cellulitis-like reactions and the development of Wells syndrome during adalimumab administration have been described $[6,7]$. Comparable to our observation, Boura et al. [6] showed that the eosinophil pathology was associated with adalimumab. In addition, a patient with no history of atopy developed asthma during adalimumab therapy [8]. Vester et al. [9] reported a woman suffering from acrodermatitis continua of Hallopeau who had been treated with adalimumab and developed a transient blood eosinophilia. Moreover Cancelliere et al.
[10] could show a connection between infliximab and etanercept administration and eosinophilia in a female patient treated for rheumatoid arthritis. The patient also developed clinical symptoms in terms of a subacute prurigo [10].

Eosinophilia is stated as a less common side effect $(<1 \%)$ in the product monograph of adalimumab (Humira ${ }^{\circledR}$ ) without providing further information on the severity or association with other clinical or serological findings [11]. In the eHealthMe database, eosinophilia has been observed during adalimumab treatment in $0.07 \%$ of reported side effects [12]. The majority of patients were in the 3 rd or 5 th decade, most of them were female and in about $80 \%$ the development of eosinophilia occurred within the first 2 years of treatment [12]. Psoriasis was not in the top underlying conditions of these patients, and there was no information about the severity of eosinophilia [12].

We could not identify any other apparent explanation for the 3 patients' elevated eosinophil counts. There were no relevant parasitological infections or haematological disorders. Two patients (No. 1 and 3) had an atopic predisposition (albeit mild) that alone would have been unlikely to cause eosinophilia. Patient 1 developed severe eosinophilia after the introduction of adalimumab; 
Table 1. Clinical data of patients $1-3$

\begin{tabular}{llll}
\hline & Patient 1 & Patient 2 & Patient 3 \\
\hline Gender & male & female & male \\
Age, years & 46 & 55 & 24 \\
Disease duration, years & 30 & 13 & 11 \\
Psoriatic arthritis & yes & yes & no \\
Atopy & yes & no & yes \\
Biological used & adalimumab, etanercept & adalimumab & etanept, adalimumab \\
PASI before treatment with a biological & 11.3 & 7.7 & 15.1 \\
Trough PASI during treatment & 0.1 & 0 & 1.9 \\
Reached PASI 75 & yes & yes & yes \\
Peak eosinophil count, $\times 10^{3} / \mu l$ & 1.48 & 1.27 \\
Worsening of psoriasis during eosinophilia & no & no \\
Other symptoms or skin changes during eosinophilia & urticaria & no & no \\
Discontinuation/change of biological & yes & no & yes \\
Improvement of eosinophilia after discontinuation & yes & yes & yes \\
Treatment switch & etanercept & yes & adalimumab \\
Pathological results by haematologist & no & methotrexate & no \\
Parasitology & negative & no & negative \\
Total IgE, kU/l & 54.6 & Dientamoeba fragilis & 360 \\
Elevated ECP & yes & 24.6 & yes \\
Elevated tryptase & not determined & yes & no \\
\hline
\end{tabular}

the condition resolved after discontinuation. Patients 2 and 3 did not have eosinophilia prior to therapy. Patient 2 developed eosinophilia after the administration of adalimumab. After the withdrawal of adalimumab, the patient's haematological parameters returned to normal values. Patient 3 also developed lowgrade eosinophilia after the administration of etanercept. During a treatment-free interval, the eosinophilia disappeared and then recurred after the re-introduction of etanercept. After a switch to adalimumab, the eosinophil count rose even higher initially and then spontaneously normalized.

The mechanism of TNF inhibition leading to eosinophilia remains unclear. The generation of IgE-class-switched antibodies might lead to IgE-mediated drug hypersensitivity and subsequent eosinophilia [13, 14]. Furthermore, TNF antagonism might induce an immune deviation from the Th1 cytokine pattern of psoriasis to the Th2 phenotype [15], which can lead to eosinophilia and elevated IgE levels [16]. Quaglino et al. [15] could show that patients suffering from psoriasis present an upregulation of Th1 and Th17 in the peripheral blood and a downregulation of regulatory $\mathrm{T}$ cell subsets at baseline. Patients responding to etanercept administration showed a significant reversal of the Th1/Th17 activation indicated by a downmodulation in the mRNA expression of the hallmark target genes and cytokines Stat-3/IL-23p19 and Stat-4/IL-12p35, and a concomitant upregulation of Th2 and regulatory $\mathrm{T}$ cell subsets as shown by GATA-3, Foxp3/IL-2 and circulating CD4+CD25+ bright FoxP3 $+\mathrm{T}$ cell subsets in all responsive patients [15]. This data showed the potential involvement of CD4+ T cell modulation in the mechanisms of response induction triggered by etanercept and possibly other TNF inhibitors. CD4+ T cell modulation can be effective in reversing the psoriatic phenotype, as Ghoreschi et al. [17] showed with IL-4 therapy in psoriatic patients that induced a marked clinical improvement by upregulation of IL-4producing CD4+ T cells.

The Th1-Th2 balance shift might be the reason that during TNF antagonism eosinophilia and PASI showed a reciprocal relationship as seen in figure $1 \mathrm{a}-\mathrm{c}$. The more effective and sustained the inhibition was, the stronger the eosinophilia. Thus, in some patients a pronounced TNF- $\alpha$ blockade may amplify an immune deviation to the Th2 phenotype [18]. Although we did not assay serum levels of IL-5 in the isolated cases described here, in the future we shall screen for any potential elevation of this cytokine [19]. TNF- $\alpha$ inhibitors might also be able to influence eosinophil apoptosis. Mature eosinophils have a lifespan of only 3-5 days and are then eliminated by apoptosis $[20,21]$. The observation that adalimumab induced more pronounced effects than etanercept might reflect adalimumab's higher potential to reduce the PASI and therefore a stronger shift to Th2. Furthermore, different structural properties of both drugs may also play a role. Infliximab for example as a monoclonal antibody (but not etanercept) has been shown to induce apoptosis in lamina propria T lymphocytes in Crohn's disease [22]. Thus, the group of TNF- $\alpha$ antagonists is heterogeneous, and our findings might express this circumstance.

In general, TNF- $\alpha$ antagonists have been found to have differential effects on haematopoiesis. A psoriasis patient treated with infliximab developed severe neutrophilia [23]. In a study on chronic anaemia of patients with inflammatory bowel disease, 18 of 27 patients undergoing treatment with infliximab were anaemic; most of them had anaemia of chronic disease. Infliximab reduced disease activity and improved anaemia in 12 patients. This was mediated by an increased production of erythropoietin for the 
degree of anaemia. In vitro infliximab increased the growth of erythroid progenitors from the peripheral blood of patients with active disease [24]. Global analysis of haemoglobin levels of 5 phase III trials for Crohn's disease (CHARM trial), rheumatoid arthritis (ATTRACT, ASPIRE and START trials) and ankylosing spondylitis revealed significant improvement of anaemia by infliximab and adalimumab [25-27]. Etanercept has even been used as a successful salvage treatment in severe aplastic anaemia [28].

On the other hand, blocking TNF- $\alpha$ can also have myelosuppressive effects. Infliximab has been used on a series of myelodysplastic patients with partial success [29]. Etanercept led to aplastic anaemia complicated by sepsis in a patient with rheumatoid arthritis [30].

Infliximab produced severe neutropenia in a patient with rheumatoid arthritis, and rechallenge with infliximab as well as etanercept led to the same effect, arguing for a class effect in the respective patient [31]. Another report concerned infliximab-induced thrombocytopenia and neutropenia [32]. Adalimumab led to neutropenia in 2 cases $[33,34]$, in 1 instance associated with expansion of the T-large granular lymphocyte compartment [34].

Taken together, eosinophilia is a rare side effect of anti-TNF- $\alpha$ treatment. These case reports underline the importance of the early identification and reporting of potentially drug-induced adverse events. Side effects such as isolated eosinophilia are not clinically detectable but can potentially lead to severe organ damage caused by the release of toxic granule proteins (such as eosinophil-derived neurotoxin, ECP, eosinophil peroxidase and eosinophil major basic protein) [35]. This should be taken into account when persistent eosinophilia is identified during TNF- $\alpha$ inhibition.

\section{Acknowledgement}

This study was supported by the Department of Dermatology, University Hospital of Zurich.

\section{Disclosure Statement}

None of the authors have any relevant financial relationship to this work.

\section{References}

1 Schon MP, Boehncke WH: Psoriasis. N Engl J Med 2005;352:1899_ 1912.

- 2 Gordon KB, Langley RG, Leonardi C, Toth D, Menter MA, Kang S, Heffernan M, Miller B, Hamlin R, Lim L, Zhong J, Hoffman R, Okun MM: Clinical response to adalimumab treatment in patients with moderate to severe psoriasis: double-blind, randomized controlled trial and open-label extension study. J Am Acad Dermatol 2006;55:598-606.

-3 Van de Kerkhof PC, Segaert S, Lahfa M, Luger TA, Karolyi Z, Kaszuba A, Leigheb G, Camacho FM, Forsea D, Zang C, Boussuge MP, Paolozzi L, Wajdula J: Once weekly administration of etanercept $50 \mathrm{mg}$ is efficacious and well tolerated in patients with moderate-to-severe plaque psoriasis: a randomized controlled trial with open-label extension. $\mathrm{Br}$ J Dermatol 2008;159:1177-1185.

-4 Moustou AE, Matekovits A, Dessinioti C, Antoniou C, Sfikakis PP, Stratigos AJ: Cutaneous side effects of anti-tumor necrosis factor biologic therapy: a clinical review. J Am Acad Dermatol 2009;61:486-504.

5 Stark DJ, Beebe N, Marriott D, Ellis JT, Harkness J: Dientamoebiasis: clinical importance and recent advances. Trends Parasitol 2006;22:9296.

6 Boura P, Sarantopoulos A, Lefaki I, Skendros P, Papadopoulos P: Eosinophilic cellulitis (Wells' syndrome) as a cutaneous reaction to the administration of adalimumab. Ann Rheum Dis 2006;65:839-840.
7 Winfield H, Lain E, Horn T, Hoskyn J: Eosinophilic cellulitis-like reaction to subcutaneous etanercept injection. Arch Dermatol 2006;142: $218-220$.

8 Bennett AN, Wong M, Zain A, Panayi G, Kirkham B: Adalimumabinduced asthma. Rheumatology (Oxford) 2005;44:1199-1200.

9 Vester K, Ruger RD, Harth W, Simon JC: Transient blood eosinophilia during treatment with adalimumab. J Eur Acad Dermatol Venereol, E-pub ahead of print.

10 Cancelliere N, Barranco P, Vidaurrazaga C, Benito DM, Quirce S: Subacute prurigo and eosinophilia in a patient with rheumatoid arthritis receiving infliximab and etanercept. J Investig Allergol Clin Immunol 2011;21:248-249.

11 Product monograph pr Humira ${ }^{\circledR}$ adalimumab $40 \mathrm{mg}$ in $0.8 \mathrm{ml}$ sterile solution $(50 \mathrm{mg} / \mathrm{ml})$ subcutaneous injection. http://www.abbott.ca/ static/cms_workspace/en_CA/content/document/HUMIRA-PM21JUL11.pdf (accessed October 16, 2011).

12 eHealthMe. http://www.ehealthme.com/ds/humira/eosinophilia (accessed October 16, 2011).

13 Pichler WJ: Adverse side-effects to biological agents. Allergy 2006;61: 912-920.

14 Hausmann OV, Seitz M, Villiger PM, Pichler WJ: The complex clinical picture of side effects to biologicals. Med Clin North Am 2010;94:791804, xi-xii.

15 Quaglino P, Bergallo M, Ponti R, Barberio E, Cicchelli S, Buffa E, Comessatti A, Costa C, Terlizzi ME, Astegiano S, Novelli M, Cavallo R, Bernengo MG: Th1, Th2, Th17 and regulatory T cell pattern in psoriatic patients: modulation of cytokines and gene targets induced by etanercept treatment and correlation with clinical response. Dermatology 2011;223:57-67.

- 16 Larche M, Akdis CA, Valenta R: Immunological mechanisms of allergen-specific immunotherapy. Nat Rev Immunol 2006;6:761-771.

17 Ghoreschi K, Thomas P, Breit S, Dugas M, Mailhammer R, van Eden W, van der Zee R, Biedermann T, Prinz J, Mack M, Mrowietz U, Christophers E, Schlondorff D, Plewig G, Sander CA, Rocken M: Interleukin- 4 therapy of psoriasis induces $\mathrm{Th} 2$ responses and improves human autoimmune disease. Nat Med 2003;9:40-46.

18 Eyerich S, Onken AT, Weidinger S, Franke A, Nasorri F, Pennino D, Grosber M, Pfab F, Schmidt-Weber CB, Mempel M, Hein R, Ring J, Cavani A, Eyerich K: Mutual antagonism of T cells causing psoriasis and atopic eczema. N Engl J Med 2011;365:231-238.

19 Simon HU, Plotz SG, Dummer R, Blaser K: Abnormal clones of T cells producing interleukin-5 in idiopathic eosinophilia. N Engl J Med 1999; 341:1112-1120.

20 Hebestreit H, Dibbert B, Balatti I, Braun D, Schapowal A, Blaser K, Simon HU: Disruption of Fas receptor signaling by nitric oxide in eosinophils. J Exp Med 1998;187:415-425.

-21 Simon HU, Yousefi S, Dibbert B, Levi-Schaffer F, Blaser K: Anti-apoptotic signals of granulocyte-macrophage colony-stimulating factor are transduced via Jak2 tyrosine kinase in eosinophils. Eur J Immunol 1997;27:3536-3539.

22 Van den Brande JM, Braat H, van den Brink GR, Versteeg HH, Bauer CA, Hoedemaeker I, van Montfrans C, Hommes DW, Peppelenbosch MP, van Deventer SJ: Infliximab but not etanercept induces apoptosis in lamina propria T-lymphocytes from patients with Crohn's disease. Gastroenterology 2003;124:1774-1785.

23 De Oliveira JP, Levy A, Morel P, Guibal F: Severe neutrophilia induced by infliximab for psoriasis. Br J Dermatol 2008;158:200-201.

24 Bergamaschi G, Di Sabatino A, Albertini R, Ardizzone S, Biancheri P, Bonetti E, Cassinotti A, Cazzola P, Markopoulos K, Massari A, Rosti V, Porro GB, Corazza GR: Prevalence and pathogenesis of anemia in inflammatory bowel disease: influence of anti-tumor necrosis factor-alpha treatment. Haematologica 2010;95:199-205.

25 Rubin DT, Mulani P, Chao J, Pollack PF, Bensimon AG, Yu AP, Ghosh $S$ : Effect of adalimumab on clinical laboratory parameters in patients with Crohn's disease: results from the CHARM trial. Inflamm Bowel Dis 2011, E-pub ahead of print. 
-26 Braun J, van der Heijde D, Doyle MK, Han C, Deodhar A, Inman R, de Vlam K, Burmester GR, Van den Bosch F, Xu S, Visvanathan S, Rahman MU: Improvement in hemoglobin levels in patients with ankylosing spondylitis treated with infliximab. Arthritis Rheum 2009;61: 1032-1036.

-27 Doyle MK, Rahman MU, Han C, Han J, Giles J, Bingham CO 3rd, Bathon J: Treatment with infliximab plus methotrexate improves anemia in patients with rheumatoid arthritis independent of improvement in other clinical outcome measures - a pooled analysis from three large, multicenter, double-blind, randomized clinical trials. Semin Arthritis Rheum 2009;39:123-131.

-28 Dufour C, Giacchino R, Ghezzi P, Tonelli R, Ferretti E, Pitto A, Pistoia V, Lanza T, Svahn J: Etanercept as a salvage treatment for refractory aplastic anemia. Pediatr Blood Cancer 2009;52:522-525.

29 Raza A, Candoni A, Khan U, Lisak L, Tahir S, Silvestri F, Billmeier J, Alvi MI, Mumtaz M, Gezer S, Venugopal P, Reddy P, Galili N: Remicade as TNF suppressor in patients with myelodysplastic syndromes. Leuk Lymphoma 2004;45:2099-2104.

-30 Kuruvilla J, Leitch HA, Vickars LM, Galbraith PF, Li CH, Al-Saab S, Naiman SC: Aplastic anemia following administration of a tumor necrosis factor-alpha inhibitor. Eur J Haematol 2003;71:396-398.
31 Montane E, Salles M, Barriocanal A, Riera E, Costa J, Tena X: Antitumor necrosis factor-induced neutropenia: a case report with double positive rechallenges. Clin Rheumatol 2007;26:1527-1529.

32 Vidal F, Fontova R, Richart C: Severe neutropenia and thrombocytopenia associated with infliximab. Ann Intern Med 2003;139:W-W63.

33 Ottaviani S, Cerf-Payrastre I, Kemiche F, Pertuiset E: Adalimumabinduced neutropenia in a patient with rheumatoid arthritis. Joint Bone Spine 2009;76:312-313.

34 Theodoridou A, Kartsios C, Yiannaki E, Markala D, Settas L: Reversible T-large granular lymphocyte expansion and neutropenia associated with adalimumab therapy. Rheumatol Int 2006;27:201-202.

35 Weller PF, Bubley GJ: The idiopathic hypereosinophilic syndrome. Blood 1994;83:2759-2779.

Alexander A. Navarini

Department of Dermatology, University Hospital of Zurich Gloriastrasse 31, CH-8091 Zurich (Switzerland)

Tel. +41 44255 1111, E-Mail alexander.navarini@usz.ch 